\title{
Smart agriculture monitoring system for outdoor and hydroponic environments
}

\author{
Bijolin Edwin ${ }^{1}$, Ebenezer Veemaraj ${ }^{1}$, Pradeepa Parthiban ${ }^{2}$, Joseph Pushparaj Devarajan ${ }^{3}$, \\ Vargheese Mariadhas ${ }^{4}$, Ahila Arumuganainar ${ }^{5}$, Maheshwar Reddy ${ }^{1}$ \\ ${ }^{1}$ Department of Computer Science and Engineering, Karunya Institute of Technology and Sciences, Coimbatore, India \\ ${ }^{2}$ Department of Information Technology, PSNA College of Engineering and Technology, Dindigul, India \\ ${ }^{3}$ Department of Information Technology, Francis Xavier Engineering College, Tirunelveli, India \\ ${ }^{4}$ Department of Computer Science and Engineering, PSN College of Engineering and Technology, Tirunelveli, India \\ ${ }^{5}$ Department of Electronics and Communication Engineering, Sethu Institute of Technology, Virudhunagar, India
}

\begin{tabular}{l} 
Article Info \\
\hline Article history: \\
Received Aug 8, 2021 \\
Revised Dec 2, 2021 \\
Accepted Jan 22, 2022 \\
\hline
\end{tabular}

Keywords:

Alert messages

Communication

Conversational artificial

Global system for mobile

Intelligence

Internet of things

Smart agriculture

\begin{abstract}
Agriculture plays an important role in economic aspects in most countries like India. Numerous problems associated with farming are continuously affecting the actions that are happening in the country. A potential resolution for such issues to be eradicated, one should combine the technological advancements with current ongoing agricultural practices. Good agricultural practice will increase crop productivity and reduce unwanted water usage. Many authors have done research on temperature, nutrition, and $\mathrm{pH}$ controlled systems. But no one concentrated on alert messages sent to the mobile phone. The main objective of the proposed system measures various natural aspects that use a global system for mobile communication (GSM) module that is connected to an Arduino to transfer the data that is obtained by the sensors to an internet of things (IoT) application programming interface (API) which is a kind of cloud computing of obtained data, this data can be analyzed if needed, and an alert short message service (SMS) is sent to the cell phone/mobile phone. The alert message can be done through conversational artificial intelligence (CAI). It is the collection of technologies behind triggering the message that will be sent automatically to the mobile as an SMS if any of the sensor values that are generating are not under already specified threshold values.
\end{abstract}

This is an open access article under the CC BY-SA license.

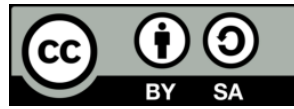

\section{Corresponding Author:}

Ebenezer Veemaraj

Department of Computer Science and Engineering, Karunya Institute of Technology and Sciences

Coimbatore, Tamilnadu, India

Email: ebenezer88@gmail.com

\section{INTRODUCTION}

Agriculture is one of the key activities for the human and other species races to survive. There is an underlying statement/advantage for agriculture, as said food to live in the main cause and there are minute chances that this long-lived practice will do its part in climate change as already said minute part. In this current period of time, food shortage is also a main concern to look upon as the agricultural land is decreasing day by day we are left with less area for agriculture [1]-[3] and lots of mouths to feed, following the previous ages agricultural techniques which most of the farmers are still using to perform agriculture will be able to cover this, we have to use the new advanced technologies to make agriculture easier and time saver. As there are many high end vast exceptional range technologies we have to select, there is a dilemma in picking the most suitable technology. In this instance, internet of things (IoT) [4] will perform this act quite well compared to others. 
There is server data storage and data extraction for analysis in the IoT field which is a major aspect of agricultural monitoring. With the help of this technology, farmers will be able to monitor the natural aspects that are linked to agricultural output. This technology can be used to focus on a single aspect as well as multiple aspects, one can monitor all these sitting at one spot.

But as there is no automation in this paper if there is something needed to be done farmers should do it manually in the field. While working on this paper, we planned to build a system that helps a farmer to monitor as many parameters as possible under the budget one can afford. As already explained in this paper the data will be transmitted to an IoT application programming interface (API) web application for visualization, for this work we chose the thingspeak IoT API because it is free to use, for the extension can include mobile API like blynk.

Agriculture is an ancient activity that has undergone many changes until now agriculture is mainly advanced in the machinery category but now it is time to move one more step and add technology for this phenomenal work. This system permits numerous devices like sensors to transmit data across the web and it will store it for further activities. There is a total of five sensors that are used in building this system. We will discuss them in depth and their roles in the following sections. One of the main advantages of this paper is it helps to reduce human error by eradicating the unknown segments in agricultural practice and by knowing the crop and field threshold values remotely the precision of farming can be improved. We hope that this paper will be a stepping stone for farmers to use currently available vast technologies to perform agriculture at the highest efficiency and to produce maximum output.

\section{RESEARCH METHOD}

The researchs proposed an IoT API to monitor the environmental conditions in a greenhouse, they built a two-node system where the sink node gets the information from the device node it will be retransmitted to a management countersuing short message service (SMS) protocol [5]-[7]. But the data can only be visible at the management center and the cost to make this paper is marginally high for a small grade farmer to afford. Prathibha et al. [8] bestowed a system that manages a greenhouse. The main purpose of this system is to make a wise irrigation system. This is used to govern the soil condition in that specified greenhouse by employing a soil sensor/moisture checker, and also it can check the air condition/humidness and temperature in the greenhouse. Introduce other sensors into the network and make it outdoor suitable. But it is only for irrigation/soil moisture and humidity and it is only proposed for a greenhouse.

A soil wet observance system that uses Arduino, sensors, and forms as a neural network to raise soil management for farmers and predict seasonal rain [9], [10]. The module used here was a Wi-Fi module, but this is difficult to work upon in a vast agricultural area. The researchers [11] proposed a technique for remote soil monitoring. In general, the diagnosing of soil properties of the sphere is dead through manual laboratory testing. However, this will be accomplished in time period through IoT, wherever some agricultural soil sensors are engaged for remote sensing.

Optimum utilization of resources [12]-[15] is crucial in time period sensor information observation when analyzing the noninheritable information. It is a real time embedded system. In the paper that they published, the applications that are covered were real time environment monitoring. They got sensors in this system and a master unit to communicate with a human interface. Joel et al. [16] developed a system for smart irrigation with a low-price tag. In this paper, the author tried to implement a smart irrigation system that costs low. Which reduces energy but increases efficiency and it is also time saving.

The main function of this is to reduce the water wastage by regulating the motor pump mechanically and choosing the water flow direction and soil wetness detector is used to gather the resulting data and this is transferred to mobile like SMS [17] and G-mail as mail. The researchers implemented an agriculture monitoring and smart irrigation system using IoT [18] and Raspberry Pi, the main aspect this author tried to resolve smart agriculture system that reduces the wastage of water, reduce the usage of fertilizers, and increase crop yield. The challenges of smart agriculture monitoring for the outdoor and hydroponic environment are given in Table 1. Many authors have done research on temperature, nutrition, and $\mathrm{pH}$-controlled systems. But no one concentrated on the alert messages sent to the mobile phone. So, the proposed system has used conversational artificial intelligence (CAI) to trigger the alert message. 
Table 1. Summary of the automated monitoring hydroponic environments

\begin{tabular}{|c|c|c|c|c|c|c|}
\hline $\begin{array}{l}\text { S. } \\
\text { No }\end{array}$ & Papers & $\begin{array}{c}\text { Crop } \\
\text { Monitoring }\end{array}$ & $\begin{array}{c}\text { Acidity } \\
\text { Monitoring }\end{array}$ & $\begin{array}{l}\text { Environment } \\
\text { Monitoring }\end{array}$ & $\begin{array}{l}\text { Nutrient } \\
\text { Monitoring }\end{array}$ & Comments \\
\hline 2 & $\begin{array}{l}\text { Nwalde and Mote } \\
{[20]}\end{array}$ & $\checkmark$ & & & $\checkmark$ & $\begin{array}{l}\text { Camera was used for monitoring the } \\
\text { plants }\end{array}$ \\
\hline 3 & $\begin{array}{l}\text { Peuchpanngarm et } \\
\text { al. [21] }\end{array}$ & $\checkmark$ & $\checkmark$ & $\checkmark$ & $\checkmark$ & $\begin{array}{l}\text { Temperature, Nutrient, and } \mathrm{pH} \text { were } \\
\text { controlled }\end{array}$ \\
\hline 4 & Omran et al. [22] & & $\checkmark$ & $\checkmark$ & $\checkmark$ & $\begin{array}{l}\text { Temperature, Nutrient and } \mathrm{pH} \text { were } \\
\text { controlled. But light was not } \\
\text { controlled }\end{array}$ \\
\hline 5 & Changmai et al. [23] & $\checkmark$ & $\checkmark$ & $\checkmark$ & $\checkmark$ & $\begin{array}{l}\text { Temperature, Nutrient, and } \mathrm{pH} \text { were } \\
\text { controlled }\end{array}$ \\
\hline 6 & $\begin{array}{l}\text { Melvix and Sridevi } \\
\text { [24] }\end{array}$ & & & $\checkmark$ & & Fuzzy logic was used to control $\mathrm{pH}$. \\
\hline 7 & $\begin{array}{l}\text { Ayala-Silva and } \\
\text { Beyl [25] }\end{array}$ & & & $\checkmark$ & & Machine reads the sensors directly. \\
\hline 11 & $\begin{array}{l}\text { Mashumah et al. } \\
\text { [29] }\end{array}$ & & $\checkmark$ & $\checkmark$ & $\checkmark$ & $\begin{array}{l}\text { Temperature, Nutrient and } \mathrm{pH} \text { were } \\
\text { controlled }\end{array}$ \\
\hline 12 & Eridani et al. [30] & & & & $\checkmark$ & Automation implemented \\
\hline
\end{tabular}

\section{PROPOSED MODEL}

Agriculture is majorly influenced by many factors which are not predictable and one of the important factors for crop cultivation is the quality of the soil. This is based on factors like soil moisture, $\mathrm{pH}$, temperature, and humidity. India is a developing country and we citizens of India are always a step ahead in terms of technology. So, our main focus is to make sure that we remove the barrier among the farmers and technology by developing a web application that is efficient, easy to access, and scalable. It is displayed in Figure 1.

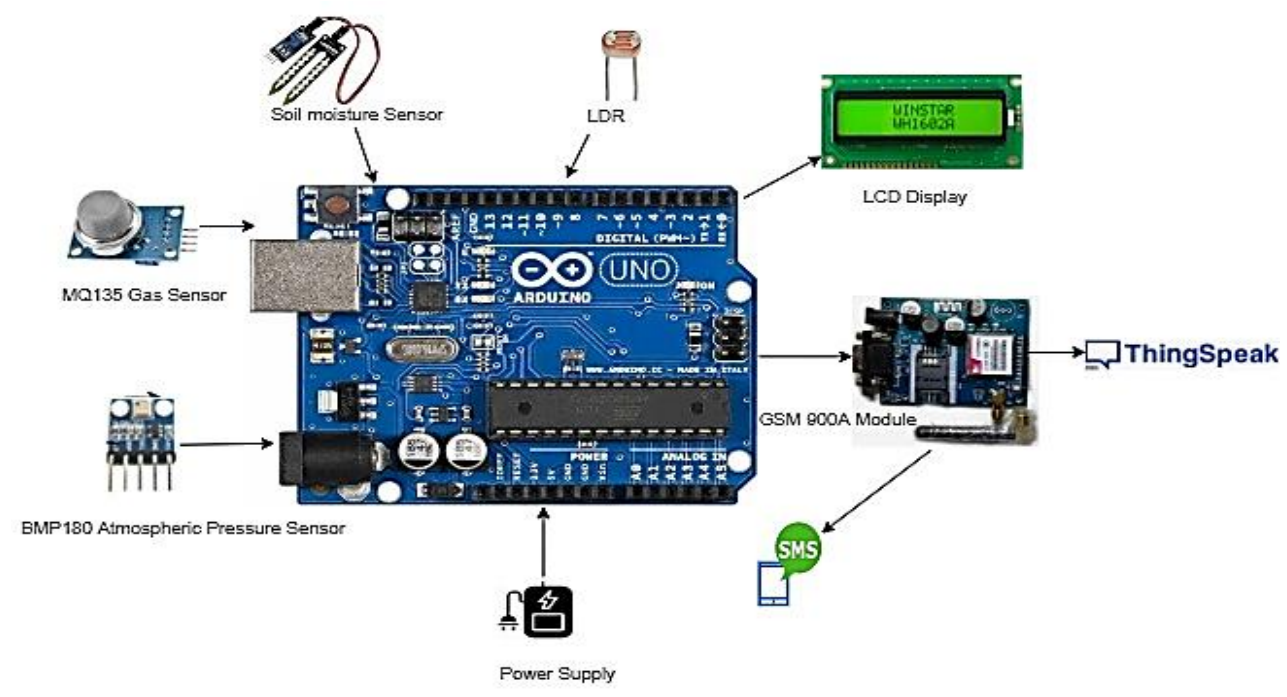

Figure 1. Smart agriculture monitoring system architecture

\subsection{Objective}

Using IoT, the proposed system tries to monitor some of the natural aspects that have a direct or indirect impact on agriculture. This is achieved by using some sensors which are available in the present-day market. The data that is obtained by the sensors will be transmitted/fed into the Arduino UNO microcontroller. The data that is fed into the Arduino Uno microcontroller will be transmitted to an IoT API using the 900A global system for mobile communication (GSM) module.

- Alert message: If the value obtained from the sensors is not in the specified threshold value an alert message will be sent as SMS. The alert message can be triggered by CAI. It is the collection of technologies behind triggering the message automatically. For the data storage and visualization, we are using Thingspeak web IoT API. 


\subsection{Components description and their uses}

\subsubsection{Gas sensor}

Gas sensor is key aspect of plant growth is the air intake and outtake, the air that is passing through the plant should not contain high levels of dangerous gases. If there is any kind of harmful gases in the atmosphere there are pretty high chances that crop will be affected and yield will be decreased. It is displayed in Figure 2. For measuring the gas in the atmosphere, we are going to use the MQ135 sensor. The max value is set at 1000 for easy segregation and the threshold value for the alert message is set according to the crop and land.

\subsubsection{LDR/photoresistor}

We all know that light is an important aspect in the growth of a plant, as they undergo photosynthesis to make food which happens with sunlight as a base element. So, this light amount is measured using a higher-grade light sensor or photoresistor. It is displayed in Figure 3. The values can be alternated as one wishes in this paper the light is obtained up to the max value of 1000 .

\subsubsection{Barometric pressure sensor}

As the name suggests the barometric pressure sensor is used to measure the atmospheric pressure, with the help of this value the weather can be predicted for the short term which helps to carry on or delay the agricultural activities. For this measuring we are going to use the BMP180 sensor, this sensor can measure three values namely adenosine triphosphate (ATP) pressure, altitude, and temperature, but we are going to extract only ATP pressure value. It is displayed in Figure 4.

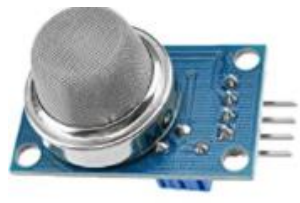

Figure 2. MQ135 Gas sensor

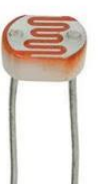

Figure 3. LDR

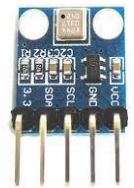

Figure 4. BMP180 Atmospheric pressure sensor

\subsubsection{Soil moisture sensor}

The plants have more water percentage compared to human bodies, we know how important water is for us, in the same way as their structure has more water than us, they need much more sophisticated water management. There are many aspects that affect the moisture in the soil, one should know the value of the amount that is in the soil to maintain the moisture content in it. The water irrigation right now has many gags. There will not be a specific water level to compare, the moisture may be high or less, there are very slight chances that moisture is in exact weightage. The soil moisture sensor will have two electrodes that are kept in the soil at a certain depth to know the moisture content. It is displayed in Figure 5. Normally the data will be given between 0 and 100 but in this paper, the data is given from the 0 to 1000 range.

\subsubsection{Temperature/Humidity sensor}

As plants are gone through many ages they have grown sensitive to temperature and humidity like many other existing species. As many species will tend to do specific activities in specific weather conditions, this holds the same for trees, the point is the plants can produce high yield if these aspects are taken care of. To do this job we are using a DHT11 sensor. Value measuring: Here two values will be obtained one being for temperature and the other being for humidity, both will be set for 100 as the maximum value. It is displayed in Figure 6.

\subsubsection{Microcontroller}

For establishing the interaction between the sensors and other components, there is a need for microcontrollers. There are many microcontrollers in today's market, for this paper we are using the Arduino Uno microcontroller. For the programming, we can use Arduino IDE. After code completion, it has to be uploaded into the Arduino Uno microcontroller board.

\subsubsection{GSM module}

GSM module is used to connect the system to an API, it is also the key component for message delivery and information transmission. For this work we have used the GSM900A module, it needs a 
$\mathrm{SIM} / \mathrm{mobile}$ number to transmit the information. There are many papers that are using general packet radio service (GPRS) for data transfer but there is a catch for it as this kind of model needs to be dispatched/deployed in an agricultural field that may be in the reach of Wi-Fi signal and security threat is also a complication, GSM module is used in this model. It is displayed in Figure 7.

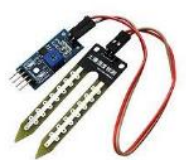

Figure 5. Soil moisture sensor

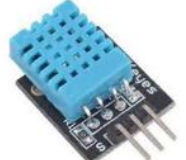

Figure 6. DHT11 humidity and temperature sensor

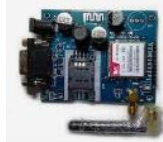

Figure 7. GSM900A module

\subsection{Block diagram of the implemented model}

The proposed model is illustrated in Figure 8. In this paper as explained in the "proposed model" section, soil moisture sensor, DHT11 snsor, MQ2 sensor, pressure sensor, and light dependent resistors (LDR) sensor will be attached to the Arduino Uno microcontroller. For the process to carry on the code will be uploaded into the microcontroller and the following actions will be carried out.

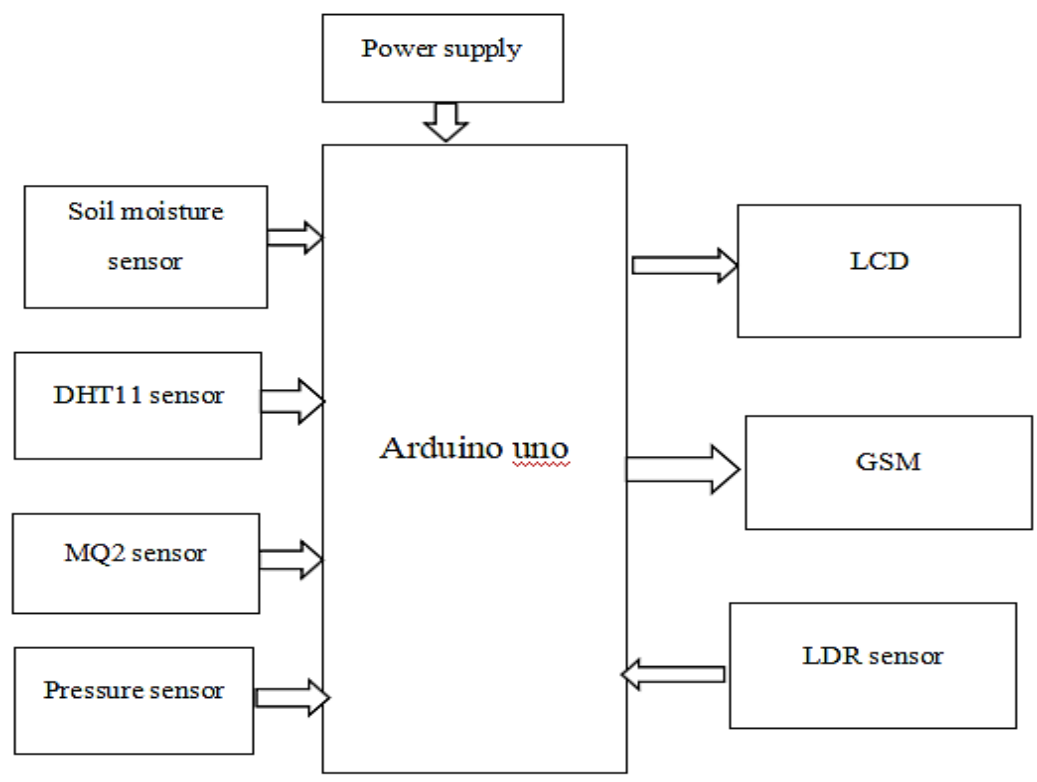

Figure 8. Block diagram of the proposed system

\section{EXPERIMENT AND RESULT}

\subsection{Data transfer}

The data that is gathered from the sensors will be transmitted to the thingspeak IoT [3] API by Arduino Uno microcontroller. The data that is gathered into the thingspeak IoT API can be exported as a ".xml" format for any further processing actions (if needed). The reason for using Thingspeak IoT API is it is much more user friendly compared to other applications. Many people used "Blynk" mobile app IoT API for this kind of paper, but in this, we didn't use the "Blynk" in this paper, there is the reason for not using the mobile app, the reason was in India there is are many people using smartphones but those smartphones are not the high-end versions those are the basic model phones in that kind of phones the IoT API mobile applications will not run smoothly, even though they run there are pretty good chances they may make phone lagging during usage, because of this reason the "Blynk" mobile application is not introduced into this paper. The temperature and humidity are measured and displayed in Figures 9 and 10 respectively. The temperature and humidity level are normal. The combination of the normal level of temperature and humidity is good for farming gas quality and soil moisture are measured and displayed in Figures 11 and 12 respectively. Light 
quantity and ATP Pressure are measured and displayed in Figures 13 and 14 respectively. They can also affect plant growth. This paper provides all the details to the user through thinkspeak IoT API.

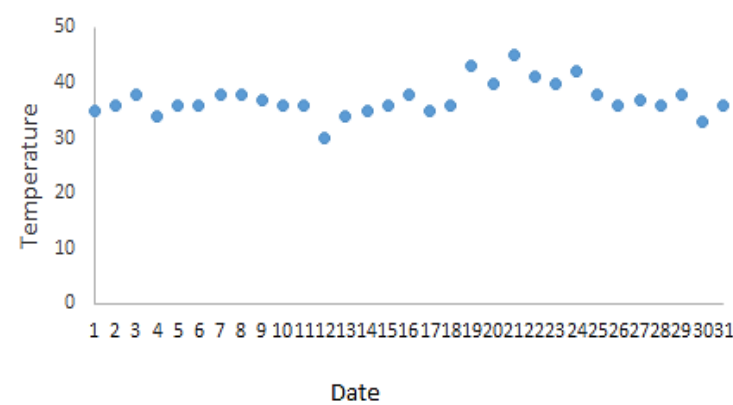

Figure 9. Temperature graph

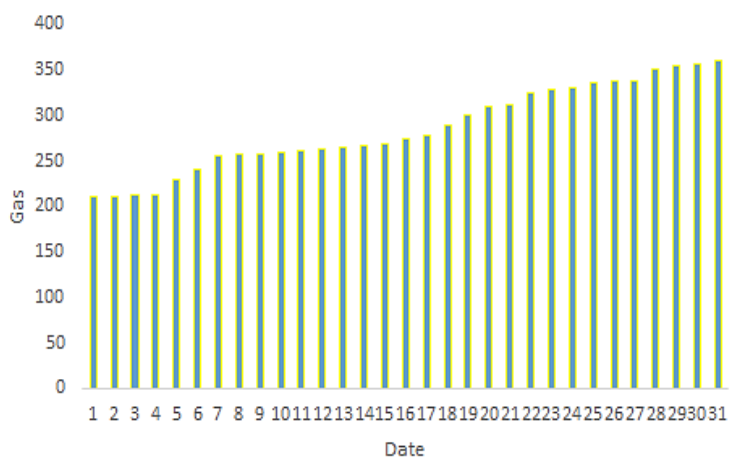

Figure 11. Gas quality graph

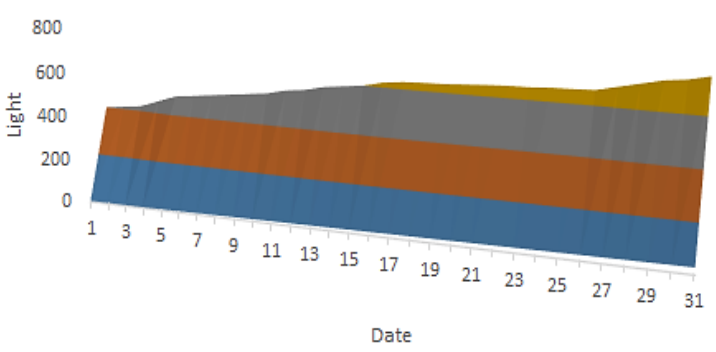

Figure 13. Light quantity graph

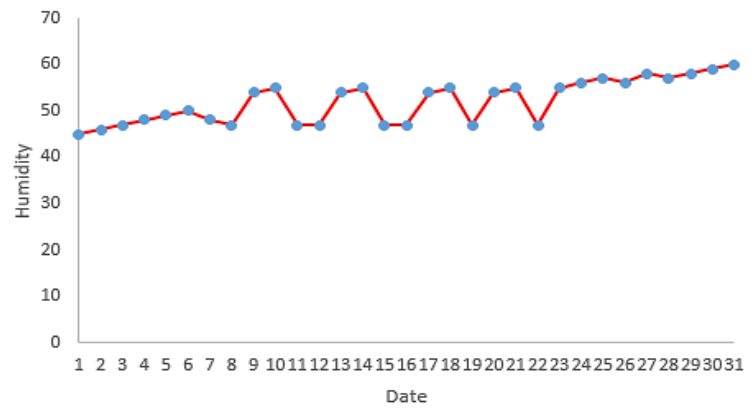

Figure 10. Humidity graph

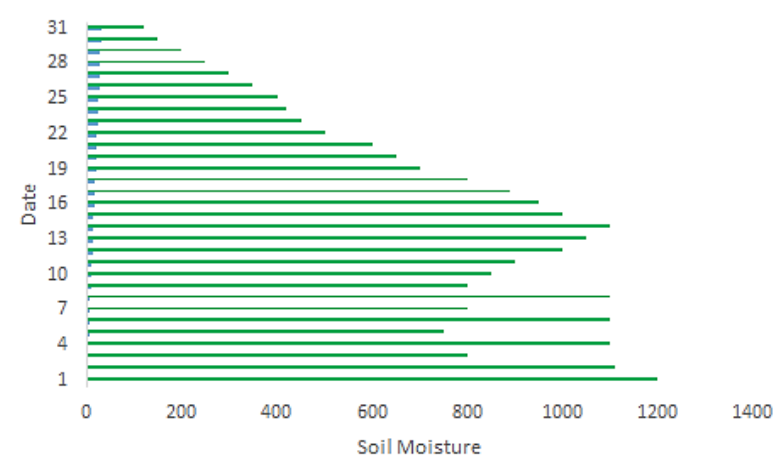

Figure 12. Soil moisture graph

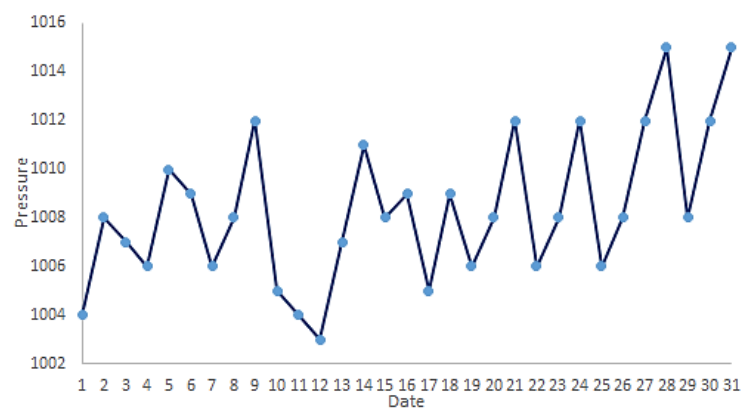

Figure 14. ATP pressure graph

\subsection{Message alert}

All the work that are literature surveyed for this paper has either, sensor data transfer to the mobile or chat box to ask for the sensor information, but in this paper, there is such thing, however, the message feature is added, but it is not as in the works that are existed till now, we added only an alert message a single worded "alert" message which is displayed in Figure 15. The alert message can be triggered by CAI. It is the collection of technologies behind triggering the message automatically. This message will be sent to the mobile as an SMS if any of the sensor values that are generated are not under already specified threshold values. The main reason for not adding the feature of sending sensor data transfer as an SMS is, there is a high-level chance that the data will be frequently updated which means the messages will be sent at frequent intervals this is a kind of irritating issue for a farmer and along with that if he has to check the data it is hard for him to figure it out in an SMS dialogue box. 


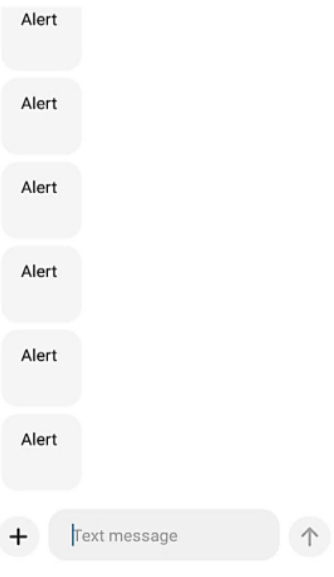

Figure 15. Messaging system

\section{CONCLUSION}

In the current time period, the IoT synchronization in various sectors is increasing day by day and according to online, it may reach up to nearly 20 billion us dollars by the end of 2022. Even in this work also IoT is used to make the agricultural area easy to overlook. With this proposed model everything will be at one's grasp and the precision in the farming will be increased. The proposed system has used CAI to trigger the alert message. The model that we described above has been implemented successfully and a prototype working model is designed and constructed. In the future, we would like to add automation and some more parameters that help to obtain better and precise statements for the farmer to carry on with agricultural activities.

\section{REFERENCES}

[1] A. Nayyar and V. Puri, "Smart farming: Iot based smart sensors agriculture stick for live temperature and moisture monitoring using arduino, cloud computing \& solar technology," in Communication and Computing Systems - Proceedings of the International Conference on Communication and Computing Systems, ICCCS 2016, Nov. 2017, pp. 673-680, doi: 10.1201/9781315364094-121.

[2] C. Kumar Sahu and P. Behera, "A low cost smart irrigation control system," in 2nd International Conference on Electronics and Communication Systems, ICECS 2015, Feb. 2015, pp. 1146-1151, doi: 10.1109/ECS.2015.7124763.

[3] C. H. Liu, B. Yang, and T. Liu, "Efficient naming, addressing and profile services in Internet-of-Things sensory environments," Ad Hoc Networks, vol. 18, pp. 85-101, Jul. 2014, doi: 10.1016/j.adhoc.2013.02.008.

[4] A. R. Yanes, P. Martinez, and R.Ahmad, "Towards automated aquaponics: A review on monitoring, IoT, and smart systems," Journal of Cleaner Production, vol. 263, 2020, doi: 10.1016/j.jclepro.2020.121571.

[5] A. A. Maroli, V. S. Narwane, R. D. Raut, and B. E. Narkhede, "Framework for the implementation of an Internet of Things (IoT)based water distribution and management system," Clean Technologies and Environmental Policy, vol. 23, no. 1, pp. 271-283, Jan. 2021, doi: 10.1007/s10098-020-01975-Z.

[6] W. Li et al., "Review of Sensor Network-Based Irrigation Systems Using IoT and Remote Sensing," Advances in Meteorology, vol. 2020, pp. 1-14, Sep. 2020, doi: 10.1155/2020/8396164.

[7] J. B. Velandia, J. S. C. Quintana, and S. C. V. Ayala, "Environment humidity and temperature prediction in agriculture using Mamdani inference systems," International Journal of Electrical and Computer Engineering, vol. 11, no. 4, pp. 3502-3509, Aug. 2021, doi: 10.11591/ijece.v11i4.pp3502-3509.

[8] S. R. Prathibha, A. Hongal, and M. P. Jyothi, "IOT Based Monitoring System in Smart Agriculture," in Proceedings - 2017 International Conference on Recent Advances in Electronics and Communication Technology, ICRAECT 2017, Mar. 2017, vol. 1325, pp. 81-84, doi: 10.1109/ICRAECT.2017.52.

[9] M. A. M. Al-Obaidi, M. A. H. Radhi, R. S. Ibrahim, and T. Sutikno, "Technique smart control soil moisture system to watering plant based on IoT with arduino uno," Bulletin of Electrical Engineering and Informatics, vol. 9, no. 5, pp. 2038-2044, Oct. 2020, doi: 10.11591/eei.v9i5.1896.

[10] S. Athani, C. H. Tejeshwar, M. M. Patil, P. Patil, and R. Kulkarni, "Soil moisture monitoring using IoT enabled arduino sensors with neural networks for improving soil management for farmers and predict seasonal rainfall for planning future harvest in North Karnataka-India," in Proceedings of the International Conference on IoT in Social, Mobile, Analytics and Cloud, I-SMAC 2017, Feb. 2017, pp. 43-48, doi: 10.1109/I-SMAC.2017.8058385.

[11] F. Karim, F. Karim, and A. Frihida, "Monitoring system using web of things in precision agriculture," Procedia Computer Science, vol. 110, pp. 402-409, 2017, doi: 10.1016/j.procs.2017.06.083.

[12] V. Sakthivelmurugan, R. Vimala, and K. R. Aravind Britto, "Magnum opus of an efficient hospitality technique for load balancing in cloud environment," Concurrency and Computation: Practice and Experience, vol. 31, no. 14, Jul. 2019, doi: 10.1002/cpe.5078.

[13] P. Parthiban and P. Raman, "Multi-objective constraint and hybrid optimisation-based VM migration in a community cloud," IET Computers and Digital Techniques, vol. 14, no. 1, pp. 37-45, Jan. 2020, doi: 10.1049/iet-cdt.2018.5243.

[14] K. Rajkumar, A. Sangeetha, V. Ebenezer, G. Ramesh, and N. Karthik, "Designing parallel operation for high-performance cloud computing using partition algorithm," in Advances in Intelligent Systems and Computing, vol. 1167, pp. 451-462, 2021.

[15] M. R. Joel, V. Ebenezer, K. A. Jeyaraj, K. Rajkumar, M. Varghese, and E. B. Edwin, "Exploiting code generation and belief propogation to Infer identity of polluters in cloud environemnt," Annals of the Romanian Society for Cell Biology, vol. 25, no. 4, pp. 10021-10027, 2021. 
[16] M. R. Joel, V. Ebenezer, N. Karthik, and K. Rajkumar, “Advance dynamic network system of internet of things,” International Journal of Recent Technology and Engineering, vol. 8, no. 3, pp. 6209-6212, Sep. 2019, doi: 10.35940/ijrte.C5657.098319.

[17] L. Boonstra, "Introduction to Conversational AI," in The Definitive Guide to Conversational AI with Dialogflow and Google Cloud, Berkeley, CA: Apress, pp. 1-27, 2021.

[18] P. Soni and J. Subhashini, "Future smart grid communication-deployment of IoT: Opportunities and challenges," Indonesian Journal of Electrical Engineering and Computer Science, vol. 23, no. 1, pp. 14-22, Jul. 2021, doi: 10.11591/ijeecs.v23.i1.pp14-22.

[19] M. Sekimoto, K. Ikeshiro, and H. Imamura, "Development of interface using marker less AR for hydroponic culture managing systems in the distant place," in Proceedings of the International Conference on Power Electronics and Drive Systems, Dec. 2018, vol. 2017-December, pp. 843-847, doi: 10.1109/PEDS.2017.8289218.

[20] R. Nalwade and T. Mote, "Hydroponics farming," in Proceedings - International Conference on Trends in Electronics and Informatics, ICEI 2017, vol. 2018-January, May 2018, pp. 645-650, doi: 10.1109/ICOEI.2017.8300782.

[21] C. Peuchpanngarm, P. Srinitiworawong, W. Samerjai, and T. Sunetnanta, "DIY sensor-based automatic control mobile application for hydroponics," in Proceedings of the 2016 5th ICT International Student Project Conference, ICT-ISPC 2016, May 2016, pp. 57-60, doi: 10.1109/ICT-ISPC.2016.7519235.

[22] M. A. Omran, W. K. Saad, B. J. Hamza, and A. Fahe, "A survey of various intelligent home applications using IoT and intelligent controllers," Indonesian Journal of Electrical Engineering and Computer Science, vol. 23, no. 1, pp. 490-499, Jul. 2021, doi: 10.11591/ijeecs.v23.i1.pp490-499.

[23] T. Changmai, S. Gertphol, and P. Chulak, "Smart Hydroponic Lettuce Farm using Internet of Things," in 2018 10th International Conference on Knowledge and Smart Technology: Cybernetics in the Next Decades, KST 2018, Jan. 2018, pp. 231-236, doi: 10.1109/KST.2018.8426141.

[24] J. S. M. L. Melvix and C. Sridevi, "Design of efficient hydroponic nutrient solution control system using soft computing based solution grading," in 2014 International Conference on Computation of Power, Energy, Information and Communication, ICCPEIC 2014, Apr. 2014, pp. 148-154, doi: 10.1109/ICCPEIC.2014.6915356.

[25] T. Ayala-Silva and C. A. Beyl, "Use of neural networks to discriminate between control leaves of wheat or those deficient in nitrogen, phosphorus, potassium, and calcium using spectral data," in Multimedia, Image Processing and Soft Computing: Trends, Principles and Applications - Proceedings of the 5th Biannual World Automation Congress, WAC 2002, ISSCI 2002 and IFMIP 2002, 2002, vol. 13, pp. 49-57, doi: 10.1109/wac.2002.1049520.

[26] T. Morimoto, T. Takeuchi, and Y. Hashimoto, "Growth optimization of plant by means of the hybrid system of genetic algorithm and neural network," in Proceedings of the International Joint Conference on Neural Networks, 1993, vol. 3, pp. 2979-2982, doi: 10.1109/ijcnn.1993.714348.

[27] M. B. Fernandes, B. A. Costa, and J. M. Lemos, "Hydroponic greenhouse crop optimization," in 13th APCA International Conference on Control and Soft Computing, CONTROLO 2018 - Proceedings, Jun. 2018, pp. 270-275, doi: 10.1109/CONTROLO.2018.8514264.

[28] A. Satoh, "A Hydroponic Planter System to enable an Urban Agriculture Service Industry," in 2018 IEEE 7th Global Conference on Consumer Electronics, GCCE 2018, Oct. 2018, pp. 722-725, doi: 10.1109/GCCE.2018.8574661.

[29] S. Mashumah, M. Rivai, and A. N. Irfansyah, "Nutrient Film Technique based Hydroponic System Using Fuzzy Logic Control," in Proceeding - 2018 International Seminar on Intelligent Technology and Its Application, ISITIA 2018, Aug. 2018, pp. 387-390, doi: 10.1109/ISITIA.2018.8711201.

[30] D. Eridani, O. Wardhani, and E. D. Widianto, "Designing and implementing the arduino-based nutrition feeding automation system of a prototype scaled nutrient film technique (NFT) hydroponics using total dissolved solids (TDS) sensor," in $20174 t h$ International Conference on Information Technology, Computer, and Electrical Engineering (ICITACEE), Oct. 2017, pp. 170175, doi: 10.1109/ICITACEE.2017.8257697

\section{BIOGRAPHIES OF AUTHORS}

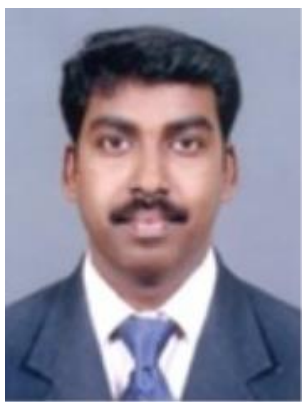

Bijolin Edwin (D) 8d SC P is an Assistant Professor at Karunya Institute of Technology and Sciences, Coimbatore, India. He holds a Ph.D. degree in the area of Cloud Computing from Anna University, Chennai, India. He received his Master of Engineering from Anna University, Chennai, India. His research interests include Cloud Computing, Deep Learning. $\mathrm{He}$ is a Lifetime Member of the Computer Society of India. He can be contacted at email: bijolin@gmail.com.

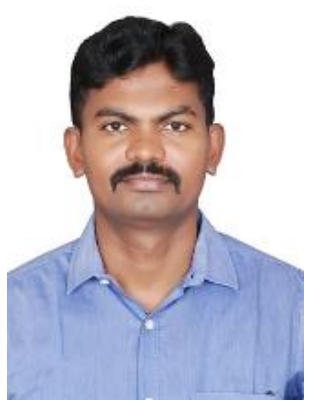

Ebenezer Veemaraj (D) 8D SC P received his B. Tech degree in Information Technology and M.E degree in Computer Science and Engineering from Anna University, Chennai in the years 2009 and 2012. He also received his Ph.D. in Information and Communication Engineering from Anna University, Chennai in the year 2020. He is currently working as an Assistant professor in the Computer Science and Engineering department, Karunya Institute of Technology and Sciences, Coimbatore Tamilnadu, India. He has published many research papers in various International/National Conferences and Journals. His area of interest includes the internet of Things, Cloud computing, Body Area Networks, Data Structures, and distributed systems. He can be contacted at email: ebenezer88@gmail.com. 

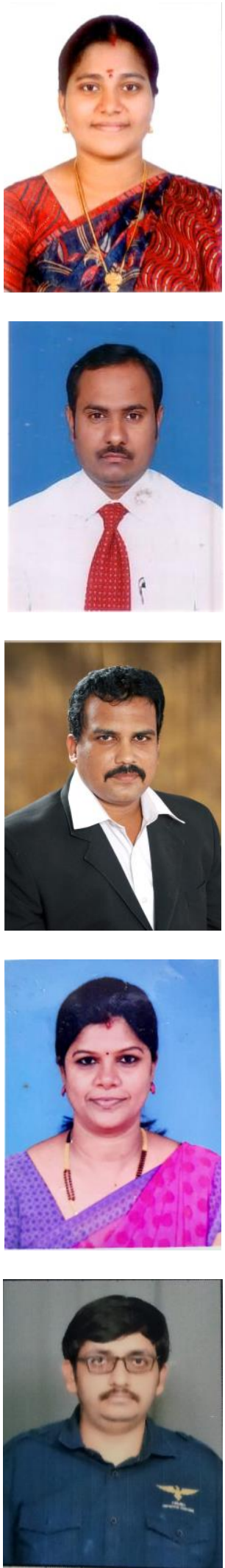

Pradeepa Parthiban (D) SC P is an Assistant Professor of Information Technology at PSNA College of Engineering and Technology (Anna University), TamilNadu, India. She received her $\mathrm{PhD}$ in Information and Communication Engineering from Anna University, Chennai, India, in 2020. She received the B. Tech degree in Information Technology from Anna University, Chennai, TamilNadu, India, in 2009, and the M.E. degree in Computer and Communication from Anna University, Chennai, India, in 2013. Her main areas of research interest are Soft Computing, Internet of Things, Wireless Networks and Data Analytics. She can be contacted at email: pradeepaselva@gmail.com.

Joseph Pushparaj Devarajan (D) SI SC P received his BE in Electronics and communication Engineering from noorul Islam college of Engineering, Tamilnadu. He received M.E in computer science Engineering from Manononmaniam Sundaranar University, Tirunelveli, Tamilnadu. He is currently working as a Assistant professor in Francis Xavier Engineering college, Tirunelveli, Tamilnadu. He has $12+$ years of experience in teaching. His area of interest are Digital image processing and Network security. He is life member of ISTE. He can be contacted at email: er.joseph.raj@gmail.com.

Vargheese Mariadhas (D) SC P received his BE in Computer Science and Engineering from Manonmaniam Sundaranar university, Tamilnadu. He received his M. Tech in Computer Science and Engineering from Dr. MGR university, Chennai, India. And also received his Doctorate in Computer Science and Engineering from St. Peter's University, Chennai, India. $\mathrm{He}$ is currently working as Professor in PSN College of Engineering and Technology, Tirunelveli, Tamilnadu. He has 20+ years of experience in both industry and teaching. His area of interest is Mobile adhoc networks, Mobile Communications and also Network security. He is a life member of ISTE. He can be contacted at email: nellaivarghese@gmail.com.

Ahila Arumuganainar (D) SC $\mathrm{SC}$ received her B.E in Electronics and Communication Engineering from National engineering College, Kovilpatti, India, in 1999, her M.E degree in Applied Electronics from Government College of Engineering, Tirunelveli, India in 2005 and her Ph.D Degree from Anna University, Chennai in 2018. She is currently working as Associate Professor in the Department of Electronics and Communication Engineering at Sethu Institute of Technology, Kariapatti TamilNadu, India. Her research interests are in the fields of Medical Imaging, Digital Image Processing. She can be contacted at email: akhilaamarnath27@gmail.com.

Maheshwar Reddy (iD) SC $\mathrm{P}$ received his B.tech degree in Computer science and Engineering from Karunya Institute of Technology and Sciences, Coimbatore, India. Currently he his working as software engineer at a company located in hyderabad. His area of research interests includes nanotechnology, Areas of applications of IoT in modern world. He can be contacted at email: maheshreddy996633@gmail.com. 